口R M NDI

\title{
O PAPEL DA MÍDIA-EDUCAÇÃO NUMA ESCOLA DE ENSINO FUNDAMENTAL
}

\section{THE ROLE OF MEDIA EDUCATION IN AN ELEMENTARY SCHOOL}

\author{
Alexandre Passos Bitencourt \\ Universidade Federal de São Paulo, SP, Brasil E-mail: alexandreletras@hotmail.com
}

DOI: https://doi.org/10.46550/amormundi.v1i1.15

Recebido em: 17.09.2020

Aceito em: 26.10.2020

\begin{abstract}
Resumo: Este texto tem como objetivo descrever como uma escola de ensino fundamental da Secretaria Municipal de Ensino da cidade de São Paulo implementou em seu currículo a área de mídia-educação para as turmas do $6^{\circ}$ ao $9^{\circ}$ ano. Como ela se encontra organizada estruturalmente, e qual o seu papel na promoçấo de ensino-aprendizagem dos estudantes. Também faz parte da análise deste texto, descrever-se o olhar de estagiárias do curso de Letras da USP, que escolheram a área de mídia-educação para fazerem o estágio e acompanharam os professores da área no segundo semestre de 2020, através das plataformas que a escola adotou como ensino remoto, devido a pandemia causada pela Covid-19. Adotou-se, para tal, princípios da mídia-educação, presentes em Beloni (2009), Bévort e Belloni (2009) e Buckingham (2010; 2012; 2019). Os resultados apontam que a opção da escola de incluir em seu currículo a área de mídia-educação foi relevante, visto que ela dialoga com as tecnologias e mídias digitais utilizadas pelos estudantes, pode, inclusive, ser uma ponte na discussão do papel da escola hoje.
\end{abstract}

Palavras-chave: Mídia-educação. Ensino. Tecnologias; Currículo.

Abstract: This paper aims to describe how an elementary school from the Secretaria Municipal de Ensino of the city of Säo Paulo implemented in its curriculum the area of media education for classes from 6th to 9th grade. How it is structurally organized, and what is its role in promoting the teaching learning of the students. It is also part of the analysis of this text, to describe the view of interns from the Letras course at USP, who chosed the media education area to do their internship and accompanied the teachers of the area in the second semester of 2020, through the platforms that the school adopted as remote teaching, due to the pandemic caused by Covid-19. To this end, was adopted principles of media education, present in Beloni (2009), Bévort and Belloni (2009) and Buckingham (2010; 2012; 2019). The results point out that the choice of the school to include in its curriculum the area of media education was relevant, since it dialogues with the technologies and digital media used by students, it can even be a bridge in the discussion of the role of the school today.

Keywords: Midia education. Teaching. Tecnologies. Curriculum.

\section{Introdução}

studos apresentados por Belloni (2009), Bévort e Belloni (2009) e Buckingham (2010;
2012; 2019), entre outros, discutidos neste texto, tem sinalizado o papel relevante da mídia-educação no currículo escolar, para tanto, não há em nível nacional um componente curricular específico com abordagem de mídia-educação para o Ensino Fundamental. Embora 
a BNCC traga à discussão a relevância da cultura digital, parece que ainda assim é pouco significativa em questóes práticas no interior das escolas, uma vez que tanto o investimento em dispositivos tecnológicos quanto na formação docente parece insuficientes, para a promoção da cultura digital no contexto de escolas de Educação Básica, principalmente, das públicas que enfrentam uma série de precariedade que vão desde a falta de recursos à super lotação de estudantes por salas de aula.

Em 2018 a EMEF Prof. Antônio Duarte de Almeida ${ }^{1}$ incluiu mídia-educação em seu currículo como área de conhecimento. Para Belloni (2009), mídia-educação é tão necessária hoje para a cidadania quanto foi a alfabetização para o séc. XIX, ou seja, a abordagem de mídia-educação na escola pode contribuir para criar uma cultura de leitura e escrita crítica aos estudantes, em relação ao que é produzido e disseminado nas mais diversas mídias digitais que, de certa forma, fazem parte da cultura deles no ensino fundamental. Em linhas gerais, significa que quanto mais cedo se apresenta e discute com os estudantes os conteúdos que circulam nas redes sociais que, majoritariamente, são parte do seu cotidiano, mais chance teremos de se construir e consolidar uma cultura de consciência entre eles, no que diz respeito ao uso e compartilhamento do que acessam diariamente dentro e fora da escola.

Segundo Tori (2017), o desafio para a educação é cada vez maior, ou seja, não basta mais que o sujeito seja alfabetizado em leitura e escrita, visto que o conceito de alfabetização foi ampliado e a distância entre "alfabetizados e analfabetos, incluídos e excluídos, pode ${ }^{2}$ ficar assustadoramente intransponível" (TORI, 2017, p. 49). Para Rojo e Moura (2019) tanto as tecnologias quanto as mídias têm apresentado constantes mudanças, no que diz respeito à recepção e produçáo das linguagens e discursos. Estar atento a esse novo paradigma que se coloca como promotor de novas culturas é importante para o ensino-aprendizagem dos estudantes deste século.

Charaudeau (2019) sinaliza que a informação e a comunicação são noçôes de fenômenos sociais e, as mídias, por sua vez, são suportes organizacionais que se apossam delas para integrálas nas lógicas: econômica, tecnológica e simbólica. E nesse sentido tornam-se objeto de atençôes do mundo político, das ciências e tecnologias, do próprio mundo midiático e do educativo "que se pergunta sobre o lugar que as mídias devem ocupar nas instituiçôes escolares e de formação profissional, de modo a formar um cidadáo consciente e crítico com relação às mensagens que os rodeiam" (CHARAUDEAU, 2019, p. 16). A inclusão das mídias no contexto educacional se torna, hoje, portanto, necessário e oportuno para a promoção do debate sobre o papel que elas têm na formação de sujeitos conscientes e críticos sobre sua própria existência dentro do espaço social em que se encontram inseridos.

Portanto, apresentar-se-á neste texto uma breve discussão e descrição dos seguintes tópicos: mídia-educação no projeto duarte, em que discorreremos brevemente sobre o projeto pedagógico de uma escola na cidade de São Paulo que incluiu mídia-educação como área de conhecimento para atender todos os estudantes do ensino fundamental II. Em, abordagem metodológica e o olhar das estagiárias sobre midia-educação, serão descritas e discutidas quatro questóes de um formulário do Google Docs. respondido por estagiárias do curso de Letras da

1 Em virtude de os PPPs da escola encontrarem-se disponíveis em: www.revistaduarte.com.br. Optou-se por utilizar neste texto o nome da escola.

2 Ênfase para sinalizar que houve alteração lexical no texto original entre aspas, devido adequaçáo referente à concordância verbal. 
USP que realizaram o estágio na escola na área de mídia-educação. Na sequência, por fim, serão tecidas as consideraçóes finais.

\section{Mídia-educaçáo no Projeto Duarte}

Mídia-educação no Projeto Duarte ${ }^{3}$ se deve em virtude da mudança no currículo da escola realizada em 2017, em que os membros da comunidade escolar decidiram romper com o currículo convencional e conservador, passaram então a organizar seu currículo por projetos de trabalho, a partir de áreas de conhecimento, quais sejam: Linguagens, português e inglês; Humanas, história e geografia; Exatas, matemática e ciências e Integradora, educação física e arte. Em 2018 mídia-educação passa a compor uma área de conhecimento na escola, devido a reorganização do ensino fundamental de nove anos (PPP, 2018 ${ }^{4}$ ). A opção da escolha dessa área converge com a escuta realizada pela Rede Municipal de Ensino de São Paulo com 43.655 estudantes. Na pergunta: fica mais fácil aprender, 57,5\% responderam que é quando usam tecnologias, jogos, música e outros recursos; Quando perguntados: para aprender melhor, seria bom que a escola tivesse, 65,2\% responderam: internet para atividades das aulas e 58,5\% que tivesse mais acesso ao laboratório de informática (COPED/SME, 2017).

Uma escuta com uma proporção de estudantes dessa magnitude pode contribuir para se ter uma ideia mais profunda do que pensam os estudantes, no entanto, pode ter um caráter nulo, na construção do currículo da escola, na medida em que não se dê o devido valor para o que apontaram os estudantes. A inclusão de mídia-educação no currículo da escola pode promover espaço para o debate das novas mídias digitais e das Tecnologias Digitais da Informação e Comunicação (TDIC) e seu papel no cenário educativo.

$\mathrm{Na}$ terceira edição da pesquisa realizada pela Fundação Telefônica foi constatado que a forma de acesso dos jovens à internet tem mudado consideravelmente no país nos últimos anos, ou seja, em 2013-2014, 71\% dos jovens usavam o celular/smartphone e 62\% o computador de mesa, em 2018-2019, 98\% dos jovens passaram a utilizar o celular/smartphone, enquanto 36\% usavam o computador de mesa (JUVENTUDES \& CONECÇÓEES 3, 2019, p. 50). De acordo com os dados apresentados fica evidente que a forma como os jovens têm acessado à internet mudou consideravelmente, portanto, a escola deve olhar para esse movimento sem, no entanto, desconsiderá-lo na organização de seu currículo.

A área de mídia-educação no Projeto Duarte tem olhado atentamente para esses dados, para construir os conteúdos dos projetos de trabalho da área, isto é, são dados relevantes que não devem ser ignorados pela escola. Para Bitencourt (2020), mídia-educação no Projeto Duarte é uma área autônoma que tem como objetivo central trabalhar os conteúdos relacionados às mídias digitais, tendo em vista a formação de sujeitos críticos para ler, criar e participar do processo de interação de conteúdos midiáticos, a partir de três frentes que atuam de forma interconectadas, a saber: com, sobre e através das mídias (BITENCOURT, 2020).

A Figura 1 apresenta os elementos de aprendizagem de mídia-educação no Projeto Duarte.

3 Sobre o Projeto Duarte, como se encontra organizado remeto o leitor ao texto de Bitencourt (2020). Disponível em: <https://c0e13a64-7607-45ad-a19d-4c79c9d0bd5c.filesusr.com/ugd/13f659_5e238f2ac5c246c080067e6084061cf9. pdf >, e/ou aos PPPs (2017-2020) da escola. Disponíveis em: <www.revistaduarte.com.br>. Acesso em: 19 de novembro de 2020.

4 Disponível em: <https://drive.google.com/file/d/1bqkNCJFTPjK2hWiXt-sMPuMUHhtZCgwF/view>. Acesso em: 19 de novembro de 2020. 


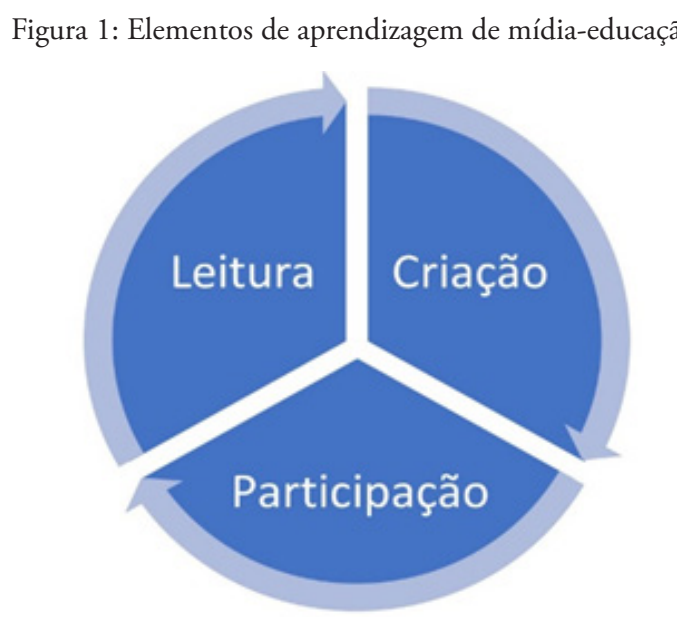

Fonte: Adaptada de Bitencourt (2020)

Os elementos de aprendizagem de mídia-educação da Figura 1 funcionam interconectados na promoção de sentido à aprendizagem. Ler é uma atividade fundamental no contexto educativo, no entanto, desenvolver nos estudantes o "prazer pela leitura" tem sido há tempos uma tarefa notadamente complexa na escola. Parece que o livro como mídia convencional que a escola tradicionalmente reconhece e apresenta aos estudantes, já não é mais suficiente para garantir e promover fluência em leitura. Olhar atentamente para as mídias digitais que os estudantes gostam e acessam para se comunicar com seus pares e aliá-las ao currículo escolar pode ser uma opção de sentido à leitura na e fora da escola.

Segundo Buckingham (2010), a mídia digital como, Internet, telefonia móvel, jogos de computador e a televisão interativa é hoje indispensável no tempo de lazer de crianças e jovens. Geralmente, quando chegam à escola nem sempre encontram espaço de interação que dialogue com a cultura de participação fora dela. Outro elemento importante em mídiaeducação é a criação de uma cultura de participação crítica dos estudantes em ambientes digitais. Principalmente, dada a relevância que a escola tem como locus que pode contribuir para que possam refletir sobre os papéis sociais que representam nas redes que participam, pois a primeira relação deles com as tecnologias digitais não ocorre no contexto escolar (BUCKINGHAM, 2010, p. 38).

Por fim, a criação é o elemento de aprendizagem de mídia-educação que, decerto, se encontra associado ao princípio de autoria do Projeto Duarte 5 . Para Buckingham (2012) é provável que ainda hoje uma parte consideravelmente muito pequena de usuários está, de fato, criando conteúdo original, ou seja, "a maior parte está simplesmente 'consumindo' conteúdo como sempre fez" (BUCKINGHAM, 2012, p. 46). Promover uma cultura de participação, leitura e criação no contexto escolar que exceda a simples tarefa da reprodução e cópia do estabelecido é o desafio de mídia-educação.

Para Almeida e Silva (2011), o crescente uso das tecnologias digitais, principalmente, os computadores e internet, tem marcado o desenvolvimento de uma cultura do uso das mídias. $\mathrm{O}$ trabalho de mídia-educação no contexto do Projeto Duarte, pode contribuir para a criação de uma cultura de uso das mídias digitais na escola, com ambientes mais significativos e conectados com a realidade dos estudantes, pois, como apontado por Almeida e Silva (2011, p. 5):

5 O Projeto Duarte se encontra organizado a partir de cinco princípios, quais sejam: democracia, autonomia, autoria, investigação e corresponsabilidade. 
assim, a escola, que se constitui como um espaço de desenvolvimento de práticas sociais se encontra envolvida na rede e é desafiada a conviver com as transformaçóes que as tecnologias e mídias digitais provocam na sociedade e na cultura, e que são trazidas para dentro das escolas pelos alunos, costumeiramente pouco orientados sobre a forma de se relacionar educacionalmente com esses artefatos culturais que permeiam suas práticas cotidianas.

Segundo o que preceituam Dudeney, Hochkly e Pegrum, (2016) a Web 2.0 apresenta uma série de ferramentas com base na web como, blogs, wikis, revistas digitais, redes sociais etc., voltadas à comunicação, a partir do compartilhamento e da colaboração, que pode levar usuários comuns da internet ao movimento de simples consumidores passivos de conteúdo, a produtores e colaboradores de conhecimentos dentro de uma cultura compartilhada. Ou seja, mídiaeducação consiste em um movimento dentro da escola de criação de conteúdos significativos aos estudantes do ensino fundamental, visto que ela é responsável pela junção de dois grandes elementos promotores de conhecimento na construção sócio/histórica da sociedade, quais sejam: a educação e a mídia.

Mídia-educação, portanto, tem como objetivo central ser uma área de conhecimento no Projeto Duarte para o desenvolvimento de um trabalho educativo, crítico e consciente da comunicação em torno das mídias digitais. No diálogo crítico com os estudantes sobre os conteúdos que circulam e compartilham nas redes sociais, no uso e apropriaçáo de novas tecnologias para a criação de conteúdo, na apropriação e compreensão da linguagem multimodal. Pois, "a linguagem não se refere somente aos sistemas de signos internos a uma língua, mas a sistemas de valores que comandam o uso desses signos em circunstâncias de comunicação particulares" (CHARAUDEAU, 2019, p. 33).

\section{Abordagem metodológica e o olhar das estagiárias sobre mídia-educação}

Neste tópico serão discutidas e descritas quatro questóes que foram respondidas por três estagiárias do curso de Letras da USP. Elas realizaram o estágio obrigatório da disciplina de "Metodologia do Ensino de Português II" na escola e escolheram a área de mídia-educação. Devido a pandemia da Covid-19 o estágio foi realizado de forma remota em que as estagiárias puderam acompanhar e participar de reunióes de planejamento junto aos professores da área através de plataformas como, Google Meet, Google Classroom e WhatsApp utilizadas pela escola para poder alcançar os estudantes. Aqui é importante ressaltar que, devido à limitação do uso de dados de internet, fato que, infelizmente, afeta ainda a maior camada de estudantes do ensino básico, o WhatsApp foi a mídia mais utilizada, visto que requer poucos dados de internet e, de certa forma, o acesso aos smartphones parece ter sido democratizado.

Os dados foram coletados por meio de um formulário do Google Docs., em que as respondentes, de forma voluntária, poderiam responder quatro questôes, sendo três dissertativas e uma de múltipla escolha, nesta última teriam que escolher uma opção, levando em conta a sua percepção em relação à área de mídia-educação na escola. Em respeito à privacidade de identidade, os nomes das estagiárias foram preservados, portanto, usar-se-á em substituição aos nomes delas as letras (A, B e C).

A abordagem metodológica utilizada neste estudo é de caráter qualitativo, para a descrição do olhar das estagiárias sobre a área de conhecimento de mídia-educação no Projeto 
Duarte. A função da metodologia qualitativa é analisar e interpretar aspectos com profundidade, para tentar descrever a complexidade do comportamento, sobretudo, humano (MARCONI; LAKATOS, 2009), para a descrição da percepção das estagiárias, foram transcritas as perguntas apresentadas no formulário, bem como as respostas dadas por cada uma, seguida de uma breve análise das respostas, como se segue:

Perguntadas sobre: (1) por que você escolheu a área de mídia-educação para fazer seu estágio na escola? Foram dadas as seguintes respostas (Quadro 01):

Quadro 01: Resposta das estagiárias para a questão 1

\begin{tabular}{|c|l|}
\hline Estagiária & \multicolumn{1}{c|}{ Resposta } \\
\hline A & $\begin{array}{l}\text { A escolha de mídia e educação na verdade foi uma conjunção de dois fatores o interesse } \\
\text { de conhecer um projeto novo, que não sabia muito o que esperar, e a disponibilidade } \\
\text { de horário. }\end{array}$ \\
\hline B & Porque as reuniões da área eram em um horário que eu podia participar. \\
\hline C & Escolhi a área por questões de disponibilidade de horário. \\
\hline
\end{tabular}

Fonte: Organizado pelo autor com base nos dados

Ambas as respostas apresentam um ponto de vista em comum, que é a disponibilidade de horário, inclusive, a $\mathbf{A}$ e a $\mathbf{C}$ finalizam com o mesmo argumento, a $\mathbf{B}$, embora não use o mesmo termo, isso fica subentendido. Preocupação que, geralmente, atormenta qualquer estudante de graduação, principalmente, no final do curso que precisa conciliar os trabalhos das disciplinas às vezes ainda com trabalho remunerado e a obrigação de cumprir o estágio como requisito obrigatório para concluir o curso, qualquer estudante de graduação já passou ou ainda passará por tal situação.

Das três estagiárias a $\mathbf{A}$ foi quem apresentou argumentos de interesse para conhecer a área de mídia-educação como um projeto novo, mesmo não sabendo do que se tratava. $\mathbf{B}$ e $\mathbf{C}$ apresentam o mesmo argumento, ou seja, disponibilidade de horário. Embora $\mathbf{B}$ tenha buscado disponibilidade de horário que coincidisse com o horário de reuniôes da área, que no Projeto Duarte significa um dia em que os professores se reúnem para planejar juntos, os conteúdos que irão trabalhar nos projetos de trabalho com os estudantes. Especificamente, para o período de pandemia, momento em que as estagiárias realizaram o estágio na escola, esse planejamento foi realizado por meio do Google Meet, às sextas-feiras a partir das $11 \mathrm{~h}$.

Quando se perguntou: (2) a proposta da área de mídia-educação atendeu ou não suas expectativas? Apresentaram as seguintes respostas (Quadro 02):

Quadro 02: Resposta das estagiárias para a questão 2

\begin{tabular}{|c|l|}
\hline Estagiária & \multicolumn{1}{c|}{ Resposta } \\
\hline A & $\begin{array}{l}\text { Superou, o trabalho dos professores tem sido muito interessante, eles trazem um } \\
\text { olhar muito sensível da realidade e vivência dos estudantes, aliando esforços para o } \\
\text { nosso estágio ser da melhor forma possível. }\end{array}$ \\
\hline B & $\begin{array}{l}\text { A proposta da área superou minhas expectativas! Achei muito interessante e } \\
\text { extremamente importante e pertinente. }\end{array}$ \\
\hline C & Em partes, sim. \\
\hline
\end{tabular}

Fonte: Organizado pelo autor com base nos dados 
No que diz respeito à proposta da área no Projeto Duarte, tanto a estagiária $\mathbf{A}$ quanto a $\mathbf{B}$ responderam que superou suas expectativas. Para a $\mathbf{C}$ a proposta da área atendeu em partes suas expectativas. Para A e B, mídia-educação tem uma proposta interessante, para $\mathbf{B}$ é um trabalho importante e pertinente, isso vai de encontro com o que apontou (BELLONI, 2009). Para A, os professores da área têm um olhar sensível da realidade, ou seja, reforça a ideia sinalizada por Nóvoa (2001), e que tem sido paulatinamente apropriada no Projeto Duarte, de que a escola é o locus de formação contínua dos professores, uma vez que os professores se apropriaram de mídia-educação, mesmo não tendo formação específica, dado que, em sua formação inicial, nem sempre houve abordagem tecnológica (FREIE; LEFFA, 2013).

Quando perguntadas: (3) o que você sugere como atividade que pode ser trabalhada na área de mídia-educação, pois em sua opinião pode contribuir com a aprendizagem dos estudantes? As respostas foram as seguintes (Quadro 03):

Quadro 03: Resposta das estagiárias para a questão 3

\begin{tabular}{|c|l|}
\hline Estagiária & \multicolumn{1}{|c|}{ Resposta } \\
\hline \multirow{2}{*}{ A } & $\begin{array}{l}\text { Tudo que foi trabalhado até agora é muito interessante, podcast, reportagens, } \\
\text { aliando a tecnologia e outras tantas áreas com um projeto comum de } \\
\text { educação, pensar as mídias atualmente teria que ser uma constante, visto } \\
\text { que estamos completamente cercados por estas, e aprender usá-las como } \\
\text { ferramenta importante para o desenvolvimento. }\end{array}$ \\
\hline B & $\begin{array}{l}\text { Acho que o ideal seria fazer atividades que despertem o pensamento crítico e } \\
\text { científico nos alunos, que façam eles perceberem que nem tudo que eles leem } \\
\text { na internet é verdade e os façam buscar fontes confiáveis. }\end{array}$ \\
\hline C & Um maior trabalho com a língua portuguesa. \\
\hline
\end{tabular}

Fonte: Organizado pelo autor com base nos dados

$\mathrm{Na}$ questão três as estagiárias são levadas a proporem atividade que pode ser trabalhada em mídia-educação, que julguem importante. A sugere que o trabalho desenvolvido na área é importante, bem como a inclusão de mídia na educação tem um papel importante e necessário, já que está em todos os lugares. B sugere que seja intensificado o trabalho com atividades que despertem o pensamento crítico e reflexivo dos estudantes, para que percebam como são veiculados os conteúdos que circulam na internet. C, por sua vez, sugere que seja trabalhado mais atividades referentes à língua portuguesa.

Aqui é importante destacar que o que as estagiárias propóem como atividade para a área de mídia-educação é relevante para o desenvolvimento dos projetos de trabalho com os estudantes. $\mathbf{C}$ propóe que seja trabalhado mais a língua portuguesa, por se tratar de estudante do curso Letras, tal preocupaçáo é bastante pertinente. Sem dúvida, o trabalho com a língua portuguesa é perpassado por todas as atividades de mídia-educação, inclusive, na abordagem de novas linguagens, visto que o trabalho com mídia-educação gira em torno de múltiplas linguagens.

Na questão quatro foi perguntado: (4) em sua opinião, qual a relevância da inclusão de mídia-educação no ensino fundamental? Numa questão de múltipla escolha foram apresentadas quatro alternativas em que as estagiárias poderiam escolher uma, a saber: 
( ) Relevante

( ) Irrelevante

( ) Pouco relevante

( ) Muito relevante

Para a questão quatro foi gerado o Gráfico 1, que se segue:

Gráfico 1: Relevância de mídia-educação no ensino fundamental

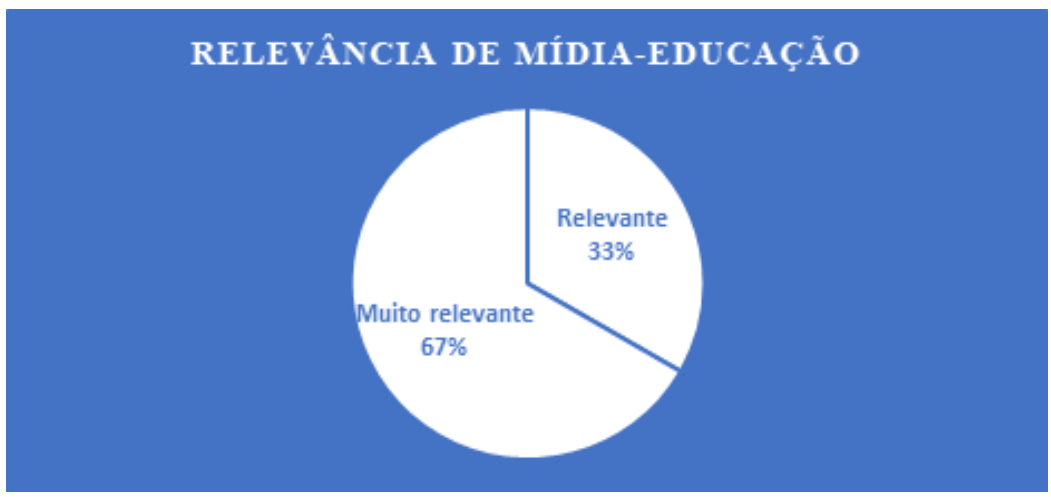

Fonte: Organizado pelo autor com base nas respostas das estagiárias

É importante destacar que não nos interessa nesse estudo analisar o que cada estagiária respondeu, portanto, na questão quatro optou-se por não apresentar de forma detalhada quem escolheu a opção relevante e muito relevante. Isto é, o objetivo é entender o papel da mídiaeducação, sob o olhar das estagiárias, descrever o quão é ou não relevante a inclusão dessa área de conhecimento no ensino fundamental.

Das quatro opçóes apresentadas na questão em discussão, apenas duas apareceram como resposta das estagiárias, sendo que para $67 \%$ das respondentes mídia-educação é muito relevante no ensino fundamental, e para 33\% é relevante. Frente aos dados apresentados nessa questão é possível afirmar que a opção de incluir mídia-educação no ensino fundamental para os estudantes no Projeto Duarte foi uma escolha importante. "Evidentemente, a simples introdução de um suporte tecnológico não significa inovação educacional. Esta só ocorrerá quando houver transformação nas metodologias de ensino e nas próprias finalidades da educação" (BELLONI, 2009, p. 92). De fato, o Projeto Duarte da forma como se encontra estruturado, com a reorganização dos elementos promotores de aprendizagem, tempos, espaços e interação, parece apresentar possibilidades metodológicas de ensino realmente inovadoras.

A mídia-educação é, de acordo com Fantin (2011, p. 28), “condição de educação para a 'cidadania instrumental e de pertencimento', para a democratização de oportunidades educacionais e para o acesso e produção de saber, o que contribui para a redução das desigualdades sociais”. A partir do fragmento e do que apontou as estagiárias sobre o trabalho de mídia-educação e seu papel no contexto do Projeto Duarte é possível afirmar que a escolha dessa área de conhecimento na escola dialoga com a necessidade que se coloca frente à educação neste século.

Para Freire (2011), a mídia-educação não resolverá as mazelas da sociedade nem tampouco da educação, porém, para o melhoramento de ambas, pode ser necessário a transformação de espectador em cidadão, nesse sentido, a "mídia-educação pode contribuir significativamente" (FREIRE, 2011, p. 54). Tal evidência pode ser constatada na resposta de $\mathbf{A}$ e $\mathbf{B}$ na questão 
três, em que foi sugerido que apresentassem sugestôes de atividades para mídia-educação que julgassem relevantes. Bem como na questão quatro em que elas apontaram ser, "relevante" e "muito relevante", o trabalho com mídia-educação na escola.

Segundo Bévort e Belloni (2009, p. 1082), "mídia-educação é um campo relativamente novo, com dificuldades para se consolidar, entre as quais a mais importante é, sem dúvida, sua pouca importância na formação inicial e continuada de profissionais da educação". A questão da formação inicial dos docentes parece que ainda precisa de muita discussão, pois fica evidente nas respostas das estagiárias que parece que tiveram pouca abordagem no quesito uso de mídias digitais, na universidade, para trabalhar com os estudantes na educação básica. A, por exemplo, na primeira questão declara que um dos fatores que a motivou escolher mídia-educação para fazer o estágio foi porque desejava conhecer um projeto novo que, na verdade, não sábia de certo do que se tratava. No entanto, quando circulam noutras questóes parece estarem bastante familiarizadas com o que é trabalhado em mídia-educação na escola.

Evidentemente a preocupação inicial de $\mathbf{A}$ desaparece tão logo que ela percebe que os conteúdos abordados em mídia-educação fazem parte do cotidiano de qualquer estudante nos dias de hoje, dentro e fora da escola, que é o uso contínuo das mídias digitais para se comunicarem com seus pares. Quando ela descobre isso começa um movimento propositivo de afirmaçáo e aprovação, em relação à proposta do currículo de mídia-educação na escola e do trabalho que os professores desenvolvem com os estudantes, na interação com eles nas plataformas digitais utilizadas para o ensino remoto, devido ao período de distanciamento social por causa da pandemia causada pela Covid-19.

\section{Consideraçóes finais}

Considerando o que se descreveu e discutiu sobre mídia-educação é possível afirmar que ela apresenta um papel relevante no contexto educativo. Discutir o papel que as mídias digitais representam na sociedade, a princípio, pode parecer pouco importante, contudo, nosso estudo mostra, tanto pela experiência nesses três anos com a inclusão de mídia-educação no currículo da escola, quanto pelas respostas das estagiárias, que as mídias ocupam um lugar no contexto educacional relevante e que não devem ser desconsideradas pela escola, visto que são parte inseparáveis da cultura dos estudantes.

Mídia-educação no Projeto Duarte tem sinalizado que mesmo com a pouca abordagem em sua formação inicial (FREIE; LEFFA, 2013), os professores têm se mostrado aptos e dispostos para experienciar outras formas de conhecimentos. Reforça a tese defendida por Nóvoa (2001), de que a escola é o locus de formação contínua dos professores, desmistifica a ideia de que a escola pública de educação básica é ruim e apenas reprodutora de conceitos prontos. Ou seja, mídia-educaçáo no Projeto Duarte deixa evidente que a escola pública, mesmo diante da escassez de recursos de todas as sortes, é capaz de criar possibilidades de inovaçáo para melhorar a aprendizagem dos estudantes.

Um ponto de vista defendido na literatura sobre mídia-educação (BELLONI, 2009; BEVÓRT; BELLONI, 2009; TUFTE; CHRISTENSEN, 2009; FREIRE, 2011; FANTIN, 2011; entre outros) é a formação de sujeitos críticos em relação aos conteúdos midiáticos. No entanto, como é possível promover reflexão crítica e significativa a respeito do que os estudantes 
fazem como participantes ou mesmo criadores de mídias? (BUCKINGHAM, 2012). Para Buckingham (2012), a tecnologia nos oferece inúmeras possibilidades de abordar essa questão e de se aproximar a teoria da prática.

No trabalho de edição e manipulação de imagens e vídeos, por exemplo, a tecnologia pode ser uma grande aliada, pois pode ajudar nos processos de escolha, seleçáo, construçáo e manipulação dos dados que se quer construir que, nas formas analógicas, "parecem estar frequentemente 'trancadas'" (BUCKINGHAM, 2012, p. 53). A proposta de mídia-educação no Projeto Duarte, portanto, segue esse viés de apropriação e usos de tecnologias digitais com os estudantes.

Outro aspecto discutido na construção das propostas de conteúdo para mídia-educação na escola é a multimodalidade, a partir do conceito apresentado por (KRESS, 2000, KESS; VAN LEEUWEN, 2001, 2006; KRESS, 2010). A multimodalidade pode ser compreendida como diferentes recursos semióticos que perpassam todas as formas de comunicação humana e, sendo assim, podem conferir novas configuraçóes linguísticas aos textos, tanto orais e escritos, quanto virtuais e imagéticos em variadas formas de interações sociais. De acordo com Kress e van Leeuwen (2001), os textos multimodais criam sentido em múltiplas articulaçôes. Os recursos multimodais estão disponíveis em todas as culturas para a criação de significados em qualquer sinalização, em todos os níveis e de qualquer modo. Tais significados são criados, predominantemente, por quatro estratos: discurso, design, produção e distribuição (Bitencourt, 2018).

A inclusão de mídia-educação no currículo da escola, portanto, de acordo com os dados apresentados e discutidos neste estudo, é relevante. Significa nesse caso que a escolha feita pela escola de incluir no seu projeto mídia-educação como área de conhecimento para atender todos os estudantes do Ensino Fundamental II foi essencial. Principalmente, porque ela dialoga com a cultura digital, e das redes notadamente ratificadas pelos estudantes. Mídia-educação pode, inclusive, estabelecer uma ponte no debate sobre o papel da escola neste século, marcado por constantes transformaçóes históricas/sociais, culturais, tecnológicas, digitais e por pandemias como, a Covid-19, que tem assolado o planeta na destruição e criação de novos hábitos culturais/ comportamentais e, certamente, educacionais que por certo foi colocado à prova e deverá ser repensado.

\section{Referências}

ALMEIDA, M.E.B.; SILVA, M.G.M. Currículo, tecnologia e cultura digital: Espaços e tempos de WebCurrículo. Revista e-curriculum, São Paulo, v.7 n.1 Abril/2011.

BELLONI, M.L. O que é mídia-educação. 3. ed. Campinas, SP: Autores Associados, 2009.

BÉVORT, E.; BELLONI, M.L. Mídia-educação: conceitos, história e perspectivas. Educ. Soc., Campinas, vol. 30, n. 109, p. 1081-1102, set./dez. 2009.

BITENCOURT. A.P. Autoritarismo do currículo e a reproduçáo do silenciamento discursivo no contexto escolar: proposta de uma escola como locus de mudança. In: SCHÜTZ, J.A.; MAYER, L.; AMARAL, M.A.F do. Um olhar sobre a educaçâo contemporânea: abrindo horizontes, construindo caminhos. Cruz Alta: Ilustração, 2020, pp. 29-42. 
BITENCOURT. A.P. Mídia-educação no projeto duarte. Revista Duarte, maio 25, 2020. Disponível em: <https:/www.revistaduarte.com.br/2020/05/midia-educacao.html>. Acesso em: 19 de novembro de 2020.

BITENCOURT. A.P. A multimodalidade na abertura de unidades e de capitulos em um livro didático de Lingua Portuguesa. Dissertação de mestrado em Letras. Universidade Federal de São Paulo, 2018.

BUCKINGHAM, D. The media education manifesto. Cambridge, UK: Polity Press, 2019.

BUCKINGHAM, D. Precisamos realmente de educação para os meios? Comunicação \& Educação, v. XVII, n. 2, p. 41-60, 2012.

BUCKINGHAM, D. Cultura Digital, Educação Midiática e o Lugar da Escolarização. Educação e Realidade, v. 35, p. 37-58, 2010.

CHARAUDEAU, P. Discurso das mídias. Tradução Angela M. S. Corrêa. 2 ed. São Paulo: Contexto, 2019.

DUDENEY, G.; HOCKLY, N.; PEGRUM, M. Letramentos digitais. Tradução: Marcos Bagno. 1. ed. São Paulo: Parábola Editorial, 2016.

FANTIN, M. Mídia-educação: aspectos históricos e teórico-metodológicos. Olhar de professor, Ponta Grossa, 14(1): 27-40, 2011. Disponível em: <http://www.revistas2.uepg.br/index.php/ olhardeprofessor>. Acesso em: 19 de novembro de 2020.

FREIRE, M.M.; LEFFA, V.J. A auto-heteroecoformação tecnológica. In: MOITA LOPES, L.P. (Org.). Linguistica aplicada na modernidade recente: festschrift para Antonieta Celani. 1. ed. São Paulo: Parábola Editorial, 2013, p. 59-78.

FREIRE. W. Mídia-educação: reflexóes e práticas de um terceiro espaço. In: FREIRE. W (Org.). Tecnologia e educação: as mídias na prática docente. 2 ed. Rio de Janeiro: Wak Ed, 2011.

JUVENTUDES E CONEXÕES. Fundação Telefônica Vivo; Rede Conhecimento Social; IBOPE Inteligência; 3.ed. --- São Paulo: Fundação Telefônica Vivo, 2019. Disponível em: $<$ http://fundacaotelefonicavivo.org.br/wp-content/uploads/pdfs/juventudes-e-conexoes3edicao-completa.pdf>. Acesso em: 19 de novembro de 2020.

KRESS, G.; VAN LEEUWEN, T. Multimodal the modes and media of contemporary communicaton discourse. London: Edward Arnald, 2001.

KRESS, G.; VAN LEEUWEN, T. Reading images: the grammar of visual design. 2nd edition. New York: Routledge, 2006.

KRESS, G. Multimodality: challenges to thinking about language. TESOL Quarterly, v.34, p. 337-340, 2000.

KRESS, G. Multimodality: a social semiotic approach to conteporary communication. London: Edward Arnald, 2010.

MARCONI, M. de A.; LAKATOS, E.M. Metodologia cientifica. 5. ed. 3 reimpr. São Paulo: Atlas, 2009. 
NOVOA, A. Professor se forma na escola. Revista Nova Escola, ano XVI, n. 14, maio 2001.

ROJO, R.H.R.; MOURA, E. Letramentos, mídias, linguagens. São Paulo: Parábola Editorial, 2019.

SÃO PAULO (SP). Projeto Político Pedagógico: EMEF

Professor Antônio Duarte de Almeida (2018). Disponível em:

< https://drive.google.com/file/d/1bqkNCJFTPjK2hWiXt-sMPuMUHhtZCgwF/view>.

Acesso em: 19 de novembro de 2020.

SÃO PAULO (SP). Secretaria Municipal de Educação. Coordenadoria Pedagógica. Currículo da Cidade: Ensino Fundamental: Língua Portuguesa. São Paulo: SME / COPED, 2017.

TORI, R. Educação sem distância: as tecnologias interativas na redução de distâncias em ensino e aprendizagem. 2 ed. Sáo Paulo: Artesanato Educacional, 2017.

TUFTE, B.; CHRISTENSEN, O. Mídia-Educação: entre a teoria e a prática. Perspectiva, Florianópolis, v. 27, n. 1, 97-118, jan./jun. 2009. 